\title{
The value of using short-format podcasts to enhance learning and teaching
}

Catherine Sutton-Brady ${ }^{\mathrm{a}}$, Karen M. Scott ${ }^{\mathrm{b}}$, Lucy Taylor ${ }^{\mathrm{a} *}$, Giuseppe Carabetta $^{\mathrm{a}}$ and Steve Clark ${ }^{\mathrm{c}}$

${ }^{a}$ Faculty of Economics and Business, University of Sydney, Sydney, Australia; ${ }^{b}$ Sydney Medical School, University of Sydney, Sydney, Australia; ${ }^{c}$ College of Fine Arts, University of New South Wales, Sydney, Australia

(Received 14 January 2009; final version received 29 July 2009)

This paper presents the findings of a podcasting trial held in 2007-2008 within the Faculty of Economics and Business at the University of Sydney, Australia. The trial investigates the value of using short-format podcasts to support assessment for postgraduate and undergraduate students. A multi-method approach is taken in investigating perceptions of the benefits of podcasting, incorporating surveys, focus groups and interviews. The results show that a majority of students believe they gained learning benefits from the podcasts and appreciated the flexibility of the medium to support their learning, and the lecturers felt the innovation helped diversify their pedagogical approach and support a diverse student population. Three primary conclusions are presented: (1) most students reject the mobile potential of podcasting in favour of their traditional study space at home; (2) what students and lecturers value about this podcasting design overlap; (3) the assessment-focussed, short-format podcast design may be considered a successful podcasting model. The paper finishes by identifying areas for future research on the effective use of podcasting in learning and teaching.

Keywords: podcasting; eLearning; flexible learning; mobile learning

\section{Introduction}

The use of technology has the potential to revolutionise university learning and teaching (Selwyn 2007). In light of this potential, much research is undertaken into technology and higher education. For example, researchers have been investigating the integration of technology into marketing curricula in marketing education (Clarke, Flaherty, and Mottner 2001; Ueltschy 2001) and the uses of software in educational psychology (Hadwin, Winne, and Nesbit 2005). A myriad of digital, electronic and mobile technological tools is available to lecturers, enabling them to enhance the learning experience. Mobile learning, focussing on the student experience, offers context-based, personal and informal aspects to higher education (Traxler 2008). The use of such technologies has increased over the years and students now have an expectation of technology use (JISC 2007). Portable, personal and situated technologies have the potential to offer students and educators flexibility in how content is delivered and how communication occurs. Mobile learning, which utilises such

*Corresponding author. Email: 1.taylor@econ.usyd.edu.au 
technologies, offers educators a means to design learning activities and resources that allow students to individualise their learning (Kukulska-Hulme, Traxler, and Pettit 2007; Traxler 2008).

While it is clear from the literature that there is an important role for technology in learning and teaching, introducing new technologies is challenging, and perhaps the greatest challenge to educators is determining its value. With this in mind, this research seeks to extend previous research on podcasting to develop a theoretical understanding of how short podcast episodes might be used to support student learning, as well as the lecturer's teaching experience. Developing an understanding of the effect on learning and teaching will help to identify potential benefits of flexible and mobile learning in general.

\section{Background}

\section{Podcasting}

Podcasting enables lecturers and students to make connections. A podcast, a portmanteau of iPod (Apple's mobile device) and broadcast (Chan, Lee, and McLoughlin 2006; Lim 2006), is a series of multimedia files pushed to users for download via the internet. All aspects of that definition are significant. A podcast is a series of episodes, linked by one syndication feed. New episodes may be automatically pushed to subscribers' personal computers, freeing users from the need to check and manually download newly available content. Podcast episodes are downloaded to users' computers (rather than streamed) and can be transferred to digital audio players, enabling mobile learning.

Some aspects of podcasting have been in use for some time. Using audio in learning and teaching, for example, has occurred for decades with some authors highlighting advantages of audio over text (Durbridge 1984; Lee, Chan, and McLoughlin 2006). Push technology, the means for information to be pushed to subscribers when they are connected to the internet, is also more than a decade old (for a review, see Franklin and Zdonik 1998). Podcasting is unique in that it combines a number of aspects, as listed above.

While podcasting has been utilised in broad scale university-wide projects (e.g., at Duke and Washington Universities) and also adopted by many individual teachers in higher education, the current literature is still somewhat limited in its assessment of the effectiveness of podcasting for student learning. There is little description of how to successfully embed podcasting in a pedagogically sound way, beyond recording lectures, and theories and design principles are in early stages of development (Sharples, Taylor, and Vavoula 2005; Herrington and Herrington 2007; Salmon and Nie 2008). Although this situation is not surprising given that podcasting has only emerged in the last five years as a learning tool, the implication is that there is still no firm evidencebased model to be replicated.

Podcasting offers a number of potential benefits relating to student learning. The first benefit to students is the ability to replay a downloaded podcast episode, enabling them to revise and confirm content, allow for further reflection and gain language clarification for non-native speakers (Laing, Wootton, and Irons 2006; Shannon 2006). A second potential learning benefit relates to the range of podcast file types available, whether audio only, enhanced (with images, links and meta information) or vodcasts (video-on-demand podcasts). Adding visual or meta information allows lecturers to create resources that appeal to a range of student learning preferences, in addition to 
auditory learners having the audio element of a podcast (Fardon 2003; Mayer and Massa 2003; Cebeci and Tekdal 2006). A third possible benefit is the student use of podcasting as a tool with which to interact with a pedagogical task. McLoughlin and Lee (2008) stress the need for constructivist models of learning and teaching that enable learner self-direction and personalisation, rather than current models that reinforce students as consumers, while Lim (2006) further frames podcasting within the cultural-historical activity theory framework, as per Engeström's (2001) concept of the subject (the student or group of students), the object (the learning required) and the activity required to achieve outcomes (the learning itself). Using the technology (podcasting), then, would be the tool that 'mediates' the activity. The fourth potential learning benefit is that podcasting enables mobile learning, that is, being able to listen to podcast episodes anywhere on a portable device. In the 2004 Duke Digital Initiative (Duke University, USA) 20 GB iPods were given to more than 1600 students to evaluate the effectiveness of iPods in learning and teaching (Belanger 2005). The project has reported a steady increase in the amount of digital media created and used by students and teachers using iPods and other portable mobile devices, such as video cameras and tablet PCs. The 2006-2007 report found that the use of multimedia resources and students' motivation had increased, and students' work had improved in quality (Belanger 2007).

General benefits include time management and an alignment with the nature of the student population. Podcasting empowers students to manage their own time (Sharples 2000), enabling them to learn at a time that best suits them, rather than during predefined lecture times. Another general benefit could relate to the student profiling work that has been undertaken by Prensky (2001) and Oblinger and Oblinger (2005). This aims to identify students as 'digital natives' (Prensky 2001) or members of the 'Net Generation' (Oblinger and Oblinger 2005) who have grown up with diverse, evolving technologies, such as podcasts. The potential benefit, then, is to be able to utilise media that are familiar to modern students. Mobile learning typically encompasses a range of these potential learning and general benefits (Traxler 2008).

Until recently, the literature has reflected that podcasting in higher education commonly refers to the distribution of recorded lectures (for example, Aldrich, Bell, and Batzel 2006; Brittain et al. 2006; Maag 2006a, 2006b; Shannon 2006; Tynan and Colbran 2006; Bell et al. 2007); few studies have looked at supplementary learning and teaching objects. This has started to change, as the literature on short-format podcasts has started to grow. Short podcast episodes have an inherent advantage over an hour-long recorded lecture as they require less time to download and consume. For busy students who balance work and study and the time travelling in between, the opportunities for short bursts of attention might be more likely (Chan and Lee 2005; Chan, Lee, and McLoughlin 2006). Similarly, Bell, Cockburn, and Wingkvisit (2007) report that in one experiment, computer science students stopped listening to podcast episodes that they considered too long ( 8 minutes).

Supplementary podcasts can have a range of potential uses in learning and teaching. Examples of studies on short podcast types include five minute summaries of presentations on discipline-specific writing workshops (Calder 2006), weekly interviews that summarise past and upcoming lecture content and remind students about events and deadlines (Bell, Cockburn, and Wingkvisit 2007), student-created 3-5 minute episodes on content background material (Lee, McLoughlin, and Chan 2008), and a series of five minute podcast episodes for revision (Evans 2008). 
Evidence of the pedagogical value of podcasting is limited in the literature. The available data suggest that most students like the flexibility of the format, however, responses vary depending on the type of content and intended purpose of the podcast for individual units of study. The effectiveness of podcasting is therefore likely to be impacted by its design and the media.

\section{Context}

This paper presents the findings of a podcasting study held in 2007 and 2008 within the Faculty of Economics and Business at the University of Sydney, Australia. The study was conducted to develop a better understanding of how short-format podcasts can be used to provide support for student-centred learning. The research questions are: (1) How and where do students listen to podcasts?; (2) When and why do students listen to podcasts in relation to other learning activities?; and (3) What are student and lecturer perceptions of the value of podcasting?

The study was undertaken in two units of study; a pilot at postgraduate level in the Masters of Commerce programme, and at undergraduate level in the Bachelor of Commerce programme over four semesters in 2007 and 2008. The pilot unit was an elective Business Marketing unit that ran in intensive mode (intensive units in the Faculty cater for non-standard delivery and are usually held in blocks of time, after hours or on weekends). In this case, the unit ran over three weekends and had an enrolment of 30 students. The lecturer introduced a short-format podcast to assist the large group of non-English speaking students in the class (over 70\%) who had traditionally struggled with assessment tasks and could potentially benefit from re-listening to assessment guidelines and requirements. The undergraduate unit, Commercial Transactions A, is a compulsory first-year foundation unit for students undertaking a major in Commercial Law in the Bachelor of Commerce programme and is an elective unit for students in other programmes. The unit runs over a standard 13-week semester and had an enrolment of a total 1548 students across four semesters. The lecturer introduced short-format podcasts for assessment-oriented content, enabling him to dedicate his time in his active, workshop-style lectures to subject-matter content.

\section{The podcasts}

The aim was to present the assessment information in an alternate format to print, although both formats were available for students via the learning management system. All podcast episodes were 10-20 minutes long and discussed assessment tasks, guidelines for approaching the assessment tasks and assessment feedback.

\section{Methodology}

A structured questionnaire was administered to students in the last session of class. In total, 30 postgraduate students were surveyed (100\% response rate) and 1548 undergraduate students (34\% response rate). The aim of this survey was to gather information on the students' familiarity with, and understanding of, podcasting and to collect data on whether the students felt their unit's short-format podcasts enhanced their learning. The pilot unit involved a structured pre-trial questionnaire that was completed in the first session of class $(100 \%$ response rate) that was deemed too cumbersome to replicate for the larger undergraduate unit of study. 
After the final class sessions, qualitative research was undertaken via one of four student focus groups (up to 10 students per focus group, moderated by a researcher other than the lecturer) and semi-structured interviews with the lecturers. By their nature, focus groups are flexible and allow discussion to take place freely, encouraging discussion (Zikmund 2000). Four students from the postgraduate pilot unit participated in the focus group, and 25 students from the undergraduate units participated. In the case of the lecturer interviews, a questionnaire was prepared as a guide for the interviewer to ensure all issues were covered, while allowing the scope of the interview to be ever-expanding (McCracken 1988). Interviews also allow for greater depth in answers and issues can be probed more deeply as they emerge.

Simple, descriptive analysis of the survey data was completed using Microsoft Excel. A grounded approach to the qualitative analysis was taken, following Glaser's lead (Glaser 1992) using QSR's NVivo. This involved creating memos and open codes, interspersed with constant comparison between codes and instances, which formulated a series of common themes discussed by students.

The research was undertaken with University of Sydney Ethics approval, with all surveys and focus group data being anonymous.

\section{Results}

\section{Student understanding and use of podcasting}

Results from the pre-trial questionnaire in the pilot study revealed that participants' understanding of podcasting was fairly limited. When asked to explain podcast, students" responses ranged from "radio TV" to the more specific "a downloadable sound file usually containing some kind of program or voice." Only half the students had downloaded a podcast before and of these students, no-one had made frequent use of podcasting. One hundred per cent of students indicated that they would like podcasting to be used in their units of study.

The post-trial questionnaire revealed that while most students in the pilot had an MP3 player, most listened to the lecturer's podcasts on their home computers (87\%). One student explained that even though MP3 players enable mobility, if one wants to do well, one has to concentrate: being mobile while listening to podcasts introduces distractions and is not always an option when studying.

Similarly, the undergraduate post-trial questionnaire shows that while $87 \%$ of students owned MP3 players (such as iPods), 76\% listened to the podcasts on their computers at home. Comments from the focus groups reveal that students see an advantage in listening to podcasts on portable MP3 players, but the contextual nature of their study meant it suited them better to listen at home, in reach of other learningrelated tools and resources. One student explained, "I took notes when [my lecturer] was speaking in the podcast" and another stated, "I listened to it at home on the computer; I was structuring my essay at the time." Another student who simply preferred listening in the comfort of his home said, "I was just on my bed... while I was listening to it... it was generally to get my head in the space."

\section{Expectation versus reality: student use of podcasting}

As a result of carrying out a pre- and post-trial questionnaire in the postgraduate unit of study, we were able to compare students' expectations of how they would use the 
Table 1. Undergraduate student expectation versus use of podcasting $(\mathrm{N}=30)$.

\begin{tabular}{lcc}
\hline & Pre-trial & Post-trial \\
\hline To prepare for a lecture & $67 \%$ & $27 \%$ \\
After the lecture as content was complex & $63 \%$ & $50 \%$ \\
After the lecture as English is not my first language & $57 \%$ & $47 \%$ \\
After the lecture as I have difficulty hearing & $33 \%$ & $23 \%$ \\
After the lecture for revision & $70 \%$ & $66 \%$ \\
To replace lectures so I don't have to attend & $23 \%$ & $3 \%$ \\
To reinforce information for assessment & $60 \%$ & $47 \%$ \\
Other & $10 \%$ & $3 \%$ \\
\hline
\end{tabular}

podcasts with the reality after the fact. Table 1 provides a comparison of responses across two, four-part questions and this comparative data gives us interesting information on perceived versus actual use of podcasts. In terms of when students used the podcasts, their predictions before the trial differed somewhat to their responses in the post-trial questionnaire, as shown in Table 1.

Table 1 shows that fewer postgraduate students used the podcasts to prepare for class than intended to (27\% compared with $67 \%)$. We can also see that students listened to the podcasts after their lectures for a range of reasons, including two-thirds who listened for revision and half who listened because the content was complex. Additionally, approximately half the students listened to the podcasts to prepare for assessment, which was the purpose of the podcasts.

Most undergraduate students $(86 \%)$, as seen in Table 2, said they listened to their lecturer's podcast at home (e.g., on a computer), with fewer than expected saying they listened while in transit using a portable media player.

The post-trial questionnaire with undergraduate students reveals similar trends in some areas, as shown in Table 3.

Table 2. Where student listened to the podcasts $(\mathrm{N}=532)$.

\begin{tabular}{lc}
\hline & Undergraduate \\
\hline At home (e.g. on my computer) & $83 \%$ \\
In transit (e.g. using a portable MP3 player) & $14 \%$ \\
Somewhere else & $3 \%$ \\
\hline
\end{tabular}

Table 3. Undergraduate and postgraduate student use of podcasting.

\begin{tabular}{lcc}
\hline & $\begin{array}{c}\text { Postgraduate } \\
\mathrm{N}=30\end{array}$ & $\begin{array}{c}\text { Undergraduate } \\
\mathrm{N}=532\end{array}$ \\
\hline To prepare for a lecture & $27 \%$ & $13 \%$ \\
After the lecture as content was complex & $50 \%$ & $9 \%$ \\
After the lecture as English is not my first language & $47 \%$ & $12 \%$ \\
After the lecture as I have difficulty hearing & $23 \%$ & $7 \%$ \\
After the lecture for revision & $66 \%$ & $35 \%$ \\
To replace lectures so I don't have to attend & $3 \%$ & $3 \%$ \\
To reinforce information for assessment & $47 \%$ & $55 \%$ \\
\hline
\end{tabular}


We can see from Table 3 that like the postgraduate students, approximately half the undergraduate students listened to the podcasts to prepare for assessment, which, again, was the purpose of the podcasts.

\section{The value of using short-format podcasts to enhance learning and teaching}

Qualitative and quantitative data collection with students and lecturers on the value of short-format podcasts reveal a correlation across a number of areas, as demonstrated in Figure 1.

The following two sections outline the student and lecturer perceptions of the value of short-format podcasts.

\section{Student perceptions of the value of short-format podcasts}

The post-trial questionnaire on students' perceptions of podcasting is shown in Table 4.

From Table 4 we can see that the majority of students were positive in their evaluations of the short-format podcasts and would like further use of them in their studies. In the focus groups, students said they valued the concise nature of the shortformat podcasts. One student commented that the lecturer "only talks about important things in podcasts," while another said, "I just didn't want to miss any tips that he would be giving out because obviously they'd be useful."

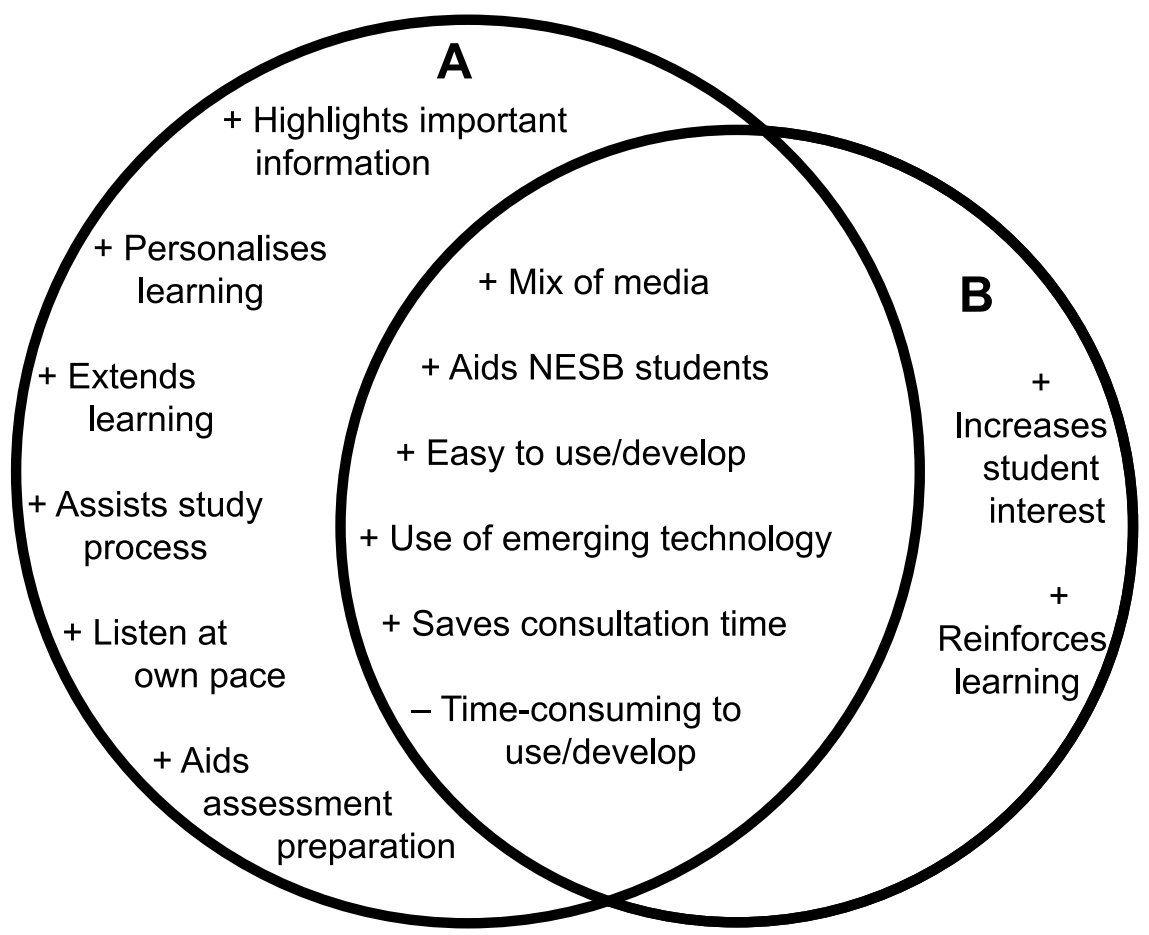

Figure 1. The value of using short-format podcasts to enhance learning and teaching for students (A) and lecturers (B). 
Table 4. Student perceptions of podcasting.

\begin{tabular}{lcc}
\hline & $\begin{array}{c}\text { Postgraduate } \\
\text { Strongly/Agree } \\
\mathrm{N}=30\end{array}$ & $\begin{array}{c}\text { Undergraduate } \\
\text { Strongly/Agree } \\
\mathrm{N}=532\end{array}$ \\
\hline Podcasting supported or enhanced my learning & $96 \%$ & $86 \%$ \\
Podcasting helped me actively engage with learning & $89 \%$ & $79 \%$ \\
I like podcasting because I can learn in my own time & $96 \%$ & $81 \%$ \\
I would like to see podcasting used in more of my units & $100 \%$ & $86 \%$ \\
$\quad$ of study & & \\
\hline
\end{tabular}

In addition, the students appreciated that the podcasts extended their learning outside of lectures. One student commented, "He didn't have to waste lecture time; he could spend other time teaching us the actual topics." Nor did the podcasts waste consultation time, as one student explained, "Instead of repeating to each student in consultation, it could save the lecturer time just doing it in one slot... It saves everyone time from waiting in consultation."

The students also liked the form of communication enabled by podcasting, in particular personalised learning. One student said "It's sort of like the lecturer's talking to you personally in a one-to-one case, rather than just discussion boards." Other students enjoyed having a mix of media in the course. One commented, "It's a nice change from having to just read, read and read" and another said, "I'm a really slow reader... [a] 15 minute podcast would take me half an hour to go through [and read] on my own."

There were also claims that the podcasts assisted the students' study process because "when you're listening to it, you're writing down notes and I think when you write and listen you retain more information than just reading it." Other students found the podcasts assisted their assessment preparation in terms of content and mental health. One said, "It allowed me to streamline particularly my exam revision and my assignment preparation" and another claimed, "When I listened to it, I just felt really calm; [I thought,] 'I'm not going to panic about this [mid-semester exam]'." The students also said podcasting allowed them flexibility when studying. One student said they liked "[the] convenience, and being able to stop and start so you can write stuff down, and if you miss something you can go back and play it again."

The students valued the podcasts for a range of other reasons. International students were positive and one said, "It's really useful to me because [our lecturer] always speaks really fast during lectures and it's really difficult for us international students to understand what he says." Finally, students commented on the ease of podcasting, with one student noting, "It's pretty idiot-proof."

\section{Lecturer perceptions of the value of short-format podcasts}

For both lecturers, the main benefit of the short-format podcasts was providing information to students about assessment. One of the lecturers stated, "That's one of the pretty strong indicators for effective learning and teaching; if you can reinforce but not... just repeat yourself." Both also saved time after lectures answering student queries. One lecturer reported, "The biggest plus for me was writing shorter emails because I was able to just send them to the podcast and say, 'The information is there, you just need to listen to it.", 
One of the lecturers believed podcasting demonstrates a lecturer's interest in students: "Once you have shown them that [you are interested in them], they tend to get more engaged with the subject." The other lecturer felt students were motivated through the use of a different medium, which correlates with the student comments. The lecturer favourably compared using a diverse range of learning and teaching tools, such as podcasts, to a more traditional "death by document" monoculture of text readings.

In addition, one of the lecturers acknowledged that podcasting is useful for students whose first language is not English. The lecturer said: "I am facing students who are really struggling with English and being able to podcast means... they can go home, they can listen to it over and over again until they get the concepts."

Finally, the lecturers said they found podcasting easy. One said, "I think that it's set up so that you can just get on to [it] and you stick your headphones on and you fire away." While admitting that podcasting "felt like a bit of an additional task on top of the many", both lecturers were positive. One concluded, "If you had to weigh up the pros and cons, there's definitely more pros." Both are keen to continue to podcast recommendations about how to approach an assessment task, general feedback on assessment tasks and summaries of readings.

\section{Discussion}

In this research, we studied the use of short-format, supplementary podcasts to develop a better understanding of how they might be used to enhance and support student learning and lecturers' teaching experiences. Three primary conclusions result from the findings: (1) most students surveyed reject the mobile potential of podcasting in favour of their traditional study habits; (2) the value of podcasting for students and lecturers often overlaps; (3) the short, assessment-focussed podcast design used in this study may be considered successful. The basis on which these conclusions were made is outlined below.

\section{Most students reject the mobile potential of podcasting in favour of their traditional study habits}

A mobile device such as a digital audio player is a personal device, that is, it is handheld or wearable (Sharples 2000). Kukulska-Hulme $(2005,1)$ notes "Learners should be able to engage in educational activities without the constraints of having to do so in a tightly delimited physical location... What is new in 'mobile learning' comes from the possibilities opened up by portable, lightweight devices." However, while most students in this study own MP3 players, few had listened to podcasts before the study and most listened to the podcasts from their home computers (Table 2). This finding is supported by other studies (Maag 2006a; Tynan and Colbran 2006; Edirisingha and Salmon 2007; Evans 2008). There are a number of possible reasons why the students in this study chose to use the podcasts in this manner.

First, based on the information gathered in the pilot study's pre-trial questionnaire, many students do not seem to have a clear understanding or full appreciation of the medium's potential benefits. This is contrary to literature that profiles today's students as digital natives (Prensky 2001) or members of the Net Generation (Oblinger 2005; Oblinger and Oblinger 2005). Such profiles build an expectation of 
today's students' information technology literacy that assumes they are comfortable and competent with technology. However, these results suggest many students do not know what podcasts are and either do not or cannot use them to their potential. Oblinger and Hawkins (2006) propose that the Net Generation's information competencies should not be confused with their confidence, as confidence using technology does not necessarily mean that information is being processed effectively or efficiently.

A second reason could be the pressure on students to keep up with class workloads. Podcasting requires time for students to up-skill and integrate a new approach into their traditional study process. This is especially evident from one student's feedback: "Although I think this is a good idea, I did not have time to use these as the course was intensive and I am extremely busy."

A final possibility, and one that is most likely when based on the qualitative evidence in this study, relates to students maintaining their study habits. Findings in other studies suggest that the majority of students used their home computers to listen to podcasts via the native audio player, as opposed to loading the podcasts on to their portable MP3 players and listening in other locations, such as on the bus or train to university (e.g., Lane 2006; Maag 2006b; Tynan and Colbran 2006). This indicates that most students are not taking advantage of the ability to use "dead time" (Bull 2005; Chan, Lee, and McLoughlin 2006) to gain broader benefits from being mobile while listening to their lecturer's podcast. As mentioned earlier, one student's statement explains that "In order to do well, one has to concentrate, so multitasking is not always an option". This is supported by findings in the IMPALA study in the UK, where one student highlighted the need to be in a particular situation while studying so they could "sit down and work, as opposed to multi-task with [the podcast]" (Edirisingha 2007, 3). Where there are high numbers of non-English speaking-background students, the need to concentrate to develop a better understanding of the podcast content may be a key factor in the learning process.

\section{The value of podcasting for students and lecturers often overlaps}

Podcasting has the potential to add real value to students' learning experiences beyond the traditional course notes and the common drill-and-practice online quiz. Our findings demonstrate that both students and lecturers valued the short-format podcasts, often for similar reasons (Figure 1). One of the great benefits of podcasting identified by both groups was that it can build on the personalised experience of engaging with the lecturer and take it beyond the classroom, expanding the lecturer's presence in the students' learning experience. This was evidenced by one student's feedback that listening to the podcast episodes felt "like the lecturer's talking to you personally in a one-to-one case." Chan, Lee, and McLoughlin (2006) and Lim (2006) support this finding and highlight the social aspect of podcasting.

For lecturers, one of the key benefits of podcasting is the knowledge that students are able to revisit key topics critical to the course learning objectives and assessment. With the increasing number of students from non-English speaking backgrounds, podcasts help reduce the need to slow down lecture delivery and repeat concepts. One student commented that podcasting allows them to revise information, whereas "[Our lecturer] doesn't have a rewind button so if you miss something in lectures, that's [it], it's gone." 
Interestingly, the lecturers and students coincided with their only criticism of the short-format podcasts. Both groups found they were easy to develop and use, and the lecturers found they saved them time answering student queries by email. However, the lecturers found the podcasts time-consuming to develop and some of the postgraduate students with "busy lives" found they lacked the time to access and use the podcasts in addition to other learning resources.

\section{The short, assessment-focussed podcast design used in this study may be considered successful}

The majority of educational podcasts involve recording lectures. Current research has identified a number of potential benefits with such podcasts for enhancing student learning, including revising lectures to clarify complex content and confirm meanings (Laing, Wootton, and Irons 2006), and self-lecturing by students (Shannon 2006). We have drawn on other researchers such as Chan, Lee, and McLoughlin (2006), Lee, Chan, and McLoughlin (2008) and Evans (2008), who found that the potential benefits of short-format and supplementary podcasting appear to be most effective when situated within a context-based learning experience. In this research, the context for both units of study was to provide the administrative, assessment-based information in a different format for students. The results demonstrate that this context-driven approach was successful in meeting that aim, as $47 \%$ of postgraduate and $55 \%$ of undergraduate students used the podcasts to support their assessment throughout the semester.

Providing a purpose and learning context for podcasting is a key theme in previous studies. This was also evidenced in our findings as the lecturers used the podcasts to reinforce learning and support assessment preparation. Interestingly, 67\% of students in the pre-trial questionnaire (Table 1) planned to use the podcasts to prepare for lectures but the podcasts were not designed for this purpose and so only $27 \%$ used them in this way. It could be concluded that many students are motivated to prepare for lectures and we need to provide appropriate learning resources to support them.

Finally, it was found that the short length of the podcast episodes was valued by the students and lecturers. The students appreciated the succinctness of them as they contain "only... important things." The design used in this study, comprising short podcast episodes of context-based content, may be one model of podcasting that is considered successful.

\section{Conclusion}

The aim of this study was to investigate the value of using short-format podcasts to support assessment for postgraduate and undergraduate students. Three clear findings emerge.

Most surveyed students reject the mobile potential of podcasting in favour of their traditional study habits. Reasons include time pressures, students' level of English language skill and knowledge of the medium.

The value of podcasting for students and lecturers often overlaps. Both groups feel it aids non-English speaking background students and is easy to use/develop. They also feel it enhances the lecturer-student interaction by allowing the relationship to go beyond the classroom in a more time-efficient manner, reducing the need for face-to-face consultation. However both feel it is time-consuming to use/develop. 
Finally the short, assessment-focussed podcast design used in this study may be considered successful since students value the succinctness of the podcast episodes and appreciate that they only contain information important to their learning.

Based on these findings, we have the following recommendations for researchers and practitioners. To increase the potential benefits of podcasting in higher education, there is a need to focus on the pedagogical design of podcasts, rather than just repeat lecture content. Our research suggests that successful examples include the development of summaries for pre-class/lecture preparation, post-class revision and extension, and assessment preparation and feedback. Given that many students do not know what podcasts are and do not or can not use the technology to its full potential, lecturers should devote class time to explaining and introducing the medium thereby informing students of the potential benefits.

Podcasting is gaining momentum in higher education. However using podcasts to supplement learning with a context-focused learning objective is still open to further investigation. Our findings highlight the need for research that focuses on appropriate learning activities and teaching strategies that use podcasting beyond content delivery.

\section{Acknowledgements}

The authors would like to acknowledge the invaluable feedback received from the two anonymous reviewers which contributed to improving this manuscript.

\section{References}

Aldrich, D., B. Bell, and T. Batzel. 2006. Automated podcasting solution expands the boundaries of the classroom. In Proceedings of the special interest group on university and college computing services conference, ed. A. Nagorsky, G. Brouilette, and C. Rodes, 14. Edmonton, Alberta: ACM 2006.

Belanger, Y. 2005. Duke University iPod first year experience final evaluation report. Durham, North Carolina: Duke University.

Belanger, Y. 2007. Summary of Duke digital initiative instructional programs 2006-2007. Durham, North Carolina: Duke University.

Bell, T., A. Cockburn, A. Wingkvisit, and R. Green, 2007. Podcasts as a supplement in tertiary education: An experiment with two computer science courses. In Proceedings of the Mobile Learning Technologies and Applications (MoLTA) conference, ed. D. Parsons and H. Ryu, 70-7. Auckland, New Zealand: Massey University.

Brittain, S., P. Glowacki, J. Van Ittersum, and L. Johnson. 2006. Podcasting lectures. Educause Quarterly 29, no. 3: 24-31.

Bull, M. 2005. No dead air! The iPod and the culture of mobile listening. Leisure Studies 24, no. 4: $343-55$.

Calder, A. 2006. If you can't beat 'em, podcast 'em. Paper presented at the 9th Pacific RimFirst Year in Higher Education Conference, 29 June-1 July, Townsville, Queensland University of Technology. http://www.fyhe.qut.edu.au/past_papers/2006/Nuts\%20\&\% 20Bolts/Calder.pdf.

Cebeci, Z., and M. Tekdal. 2006. Using podcasts as audio learning objects. Interdisciplinary Journal of Knowledge and Learning Objects 2: 46-57.

Chan, A., and M.J.W. Lee. 2005. An MP3 a day keeps the worries away: Exploring the use of podcasting to address the preconceptions and alleviate pre-class anxiety amongst undergraduate information technology students. In Good practice in practice. Proceedings of the student experience conference, ed. D.H.R. Spennemann and L. Burr, 59-71. Wagga Wagga, NSW: Charles Sturt University.

Chan, A., M.J.W. Lee, and C. McLoughlin. 2006. Everyone's learning with podcasting: A Charles Sturt University experience. In Who's learning? Whose technology? Proceedings 
of the 23rd annual ASCILITE conference, ed. L. Markhauskaite, P. Goodyear, and P. Reimann, 111-20. Sydney, NSW: University of Sydney.

Clarke III, I., T. Flaherty, and S. Mottner. 2001. Student perceptions of educational technology tools. Journal of Marketing Education 23, no. 3: 169-77.

Durbridge, N. 1984. Media in course design, No. 9, audio cassettes. In The role of technology in distance education, ed. A. Bates, 99-107. Kent: Croom Helm.

Edirisingha, P. 2007. The 'double life' of an iPod - a case study of the educational potential of new technologies. Paper presented at the EDEN Conference. Helsinki, Finland: Helsinki University of Technology. http://versicherungen-competence-center.de/elearning.nsf/ E9AF9336848D2BA7C12572D8003FE873/\$File/double_life_i-pod_edirisingha_2006. pdf.

Edirisingha, P., and G. Salmon. 2007. Pedagogical models for podcasts in higher education. https://lra.le.ac.uk/handle/2381/405.

Engeström, Y. 2001. Expansive learning at work: Toward an activity theoretical reconceptualization. Journal of Education and Work 14, no. 1: 133-56.

Evans, C. 2008. The effectiveness of m-learning in the form of podcast revision lectures in higher education. Computers and Education 50, no. 2: 491-8.

Fardon, M. 2003. Internet streaming of lectures: A matter of style. The University of Western Australia. http://www.ilecture.uwa.edu.au/misc/Fardon_MatterOfStyle.pdf.

Franklin, M., and S. Zdonik. 1998. "Data in your face": Push technology in perspective. Paper presented at the SIGMOD International Conference on Management of Data. Seattle, USA: SIGMOD.

Glaser, B. 1992. Basics of grounded theory analysis: Emergence vs. forcing. Mill Valley, CA: Sociology Press.

Hadwin, A.F., P.H. Winne, and J.C. Nesbit. 2005. Roles for software technologies in advancing research and theory in educational psychology. British Journal of Educational Psychology 75, no. 1: 1-24.

Herrington, A., and J. Herrington. 2007. Authentic mobile learning in higher education. In Proceedings of the Australian Association for Research in Education international educational research conference, ed. P.L. Jeffery. Freemantle, WA: University of Notre Dame. http://www.aare.edu.au/07pap/her07131.pdf.

Joint Information Systems Committee (JISC). 2007. Student expectations study. http:// www.jisc.ac.uk/publications/publications/studentexpectations.

Kukulska-Hulme, A. 2005. Introduction. In Mobile learning: A handbook for educators and trainers, ed. A. Kukulska-Hulme and J. Traxler, 1-3. London: Routledge.

Kukulska-Hulme, A., J. Traxler, and J. Pettit. 2007. Designed and user-generated activity in the mobile age. Journal of Learning Design 2, no.1: 52-65. http://www.jld.qut.edu.au/.

Laing, C., A. Wootton, and A. Irons. 2006. iPod! uLearn? In Proceedings of the international conference on multimedia and ICT in education, ed. A. Méndez-Vilas, A. Solano Martín, J.A. Mesa González and J. Mesa González, 514-8. Seville, Spain: Formatex.

Lane, C. 2006. Podcasting at the UW: An evaluation of current use. University of Washington Learning and Scholarly Technologies. Washington USA: University of Washington. http://catalyst.washington.edu/research_development/papers/2006/ podcasting_report.pdf.

Lee, M., A. Chan, and C. McLoughlin. 2006. Educational podcasting using the Charles Sturt University flexible publishing platform. In Proceedings of the world conference on e-learning in corporate, government, healthcare, and higher education 2006, ed. T. Reeves and S. Yamashita, 2894-901. Chesapeake, VA: AACE.

Lee, M.J.W., C. McLoughlin, and A. Chan. 2008. Talk the talk: Learner-generated podcasts as catalysts for knowledge creation. British Journal of Educational Technology 39, no. 3: 501-21.

Lim, K.Y.T. 2006. Now hear this - exploring podcasting as a tool in geography education. Singapore: National Institute of Education, Nanyang Technological University. http:// homepage.mac.com/voyager/brisbane_kenlim.pdf.

Maag, M. 2006a. iPod, uPod?: An emerging mobile learning tool in nursing education and students' satisfaction. In Who's learning? Whose technology? Proceedings of the 23rd annual ASCILITE conference, ed. L. Markhauskaite, P. Goodyear, and P. Reimann, 483-92. Sydney, NSW: University of Sydney. 
Maag, M. 2006b. Podcasting and MP3 players: Emerging education technologies. CIN: Computers, Informatics, Nursing 24, no. 1: 9-13.

Mayer, R.E., and L.J. Massa. 2003. Three facets of visual and verbal learners: Cognitive ability, cognitive style and learning preference. Journal of Educational Psychology 95, no. 4: 833-46.

McCracken, G. 1988. The long interview. California: Sage Publications.

McLoughlin, C., and M.J.W. Lee. 2008. Mapping the digital terrain: New media and social software as catalysts for pedagogical change. In Hello! Where are you in the landscape of educational technology? Proceedings of the 25th annual ASCILITE conference, ed. R. Atkinson and C. McBeath, 641-52. Melbourne, Victoria: Deakin University.

Oblinger, D. 2005. Learners, learning and technology. Educause Review 40: 67-75.

Oblinger, D.G., and B. Hawkins. 2006. The myth about student competency. Educause Review 41: 12-13.

Oblinger, D.G., and J.L. Oblinger. 2005. Is it age or IT: First steps toward understanding the net generation. In Educating the net generation, ed. D.G. Oblinger and J.L. Oblinger, 2.1-2.10. Boulder, CO: Educause.

Prensky, M. 2001. Digital natives, digital immigrants. On the Horizon 9, no. 5: 1-6.

Salmon, G., and M. Nie. 2008. Doubling the life of iPods. In Podcasting for learning in universities, ed. G. Salmon and P. Edirisingha, 1-11. Glasgow: McGraw Hill/Open University Press.

Selwyn, N. 2007. The use of computer technology in university teaching and learning: A critical perspective. Journal of Computer Assisted Learning 23, no. 2: 83-94.

Shannon, S.J. 2006. Why don't students attend lectures and what can be done about it through using iPod nanos? In Who's learning? Whose technology? Proceedings of the 23rd annual ASCILITE conference, ed. L. Markhauskaite, P. Goodyear, and P. Reimann, 753-6. Sydney, NSW: University of Sydney.

Sharples, M. 2000. The design of personal mobile technologies for lifelong learning. Computers \& Education 34, nos. 3-4: 177-93.

Sharples, M., J. Taylor, and G. Vavoula. 2005. Towards a theory of mobile learning. In Proceedings of 4th mLearn conference, ed. J. Attewell, T. Brown, G.D. Bormida, M. Sharples, and H.V.D. Merwe. Cape Town, Western Cape: mLearn. http:// www.mlearn.org.za/CD/papers/Sharples-\%20Theory\%20of\%20Mobile.pdf.

Traxler, J. 2008. Podcasting in context. In Podcasting for learning in universites, ed. G. Salmon, and P. Edirisingha, 12-19. Glasgow: McGraw Hill/Open University Press.

Tynan, B., and S. Colbran. 2006. Podcasting, student learning and expectations. In Who's learning? Whose technology? Proceedings of the 23rd annual ASCILITE conference, ed. L. Markhauskaite, P. Goodyear, and P. Reimann, 825-32. Sydney, NSW: University of Sydney.

Ueltschy, L.C. 2001. An exploratory study of integrating interactive technology into the marketing curriculum. Journal of Marketing Education 23, no. 1: 63-72.

Zikmund, W.G. 2000. Business research methods. 6th edition. Orlando, Fl.: Dryden Press. 